\title{
Electrode materials for microbial fuel cells: nanomaterial approach
}

\author{
Mustakeem $^{1}$
}

Received: 25 June 2015/Accepted: 13 October 2015/Published online: 5 November 2015

(C) The Author(s) 2015. This article is published with open access at Springerlink.com

\begin{abstract}
Microbial fuel cell (MFC) technology has the potential to become a major renewable energy resource by degrading organic pollutants in wastewater. The performance of MFC directly depends on the kinetics of the electrode reactions within the fuel cell, with the performance of the electrodes heavily influenced by the materials they are made from. A wide range of materials have been tested to improve the performance of MFCs. In the past decade, carbon-based nanomaterials have emerged as promising materials for both anode and cathode construction. Composite materials have also shown to have the potential to become materials of choice for electrode manufacture. Various transition metal oxides have been investigated as alternatives to conventional expensive metals like platinum for oxygen reduction reaction. In this review, different carbon-based nanomaterials and composite materials are discussed for their potential use as MFC electrodes.
\end{abstract}

Keywords Microbial fuel cell - Wastewater treatment . Electrode material · Carbon nanotube - Graphene . Extracellular electron transfer $\cdot$ Biocathode

Mustakeem

mustakeem.mustakeem@kaust.edu.sa

1 Division of Biological and Environmental Science and Engineering, Water Desalination and Reuse Center, King Abdullah University of Science and Technology, Thuwal 23955-6900, Saudi Arabia

\section{Introduction}

Due to a growing global population, domestic and industrial energy demands are on the rise. According to the International Energy Agency (IEA), power demand is expected to rise up to 18 billion tonne oil equivalent by 2035 from a current demand of 12 billion tonne oil equivalent [1]. Presently, most of the world's energy is derived from fossil fuels, but their efficiency, security and environmental effects hold it back from being a preferred energy resource. To meet future energy demands, there is need of a reliable, sustainable and clean energy source. While nuclear power may be an alternative means of energy, with the recent incident in Japan in 2011, the safe and reliable implementation of it remains in question [2].

In the coming decades, access to clean water will be limited in many parts of the world. Recycling of wastewater (wastewater treatment) is one of the ways in which the demand for clean drinking water can be met. At present, most existing wastewater purification technologies consume a lot of energy. According to recent reports, in the United States, water and wastewater systems consume around $5 \%$ of the total energy produced in the country, which happens to be a huge burden on the energy sector [3]. To address this inefficiency, microbial fuel cells (MFCs) can be explored to treat wastewater in a more economical and sustainable way.

An idea developed by British botanist Potter [4] in 1911 was to produce electricity using microbes that oxidize organic molecules. Since then, MFCs have attracted special attention from researchers, representing a promising solution for energy generation. MFCs treat water in addition to generating energy by consuming organic pollutants from the wastewater. Over the last 10 years, this idea has seen a tremendous interest from scientific community leading to a 
promising power source to provide power for electronic devices [5] and other practical application in a cost-effective manner [6].

The concept discovered by Potter in 1911 [4] was not well appreciated until 1999, when it was shown that bacteria can transfer electrons externally to electrodes [7]. During the last decade, this technology has been developed in a practical way for electricity generation along with wastewater treatment $[8,9]$.

Principally, the performance of MFCs can be affected by several factors including microbial inoculum, the chemical substrate in the fuel, the proton exchange membrane (PEM) and the electrode material. For the last decade, most of the research in this field has been focused on the electrode material because it directly influences the performance and as such the potential commercialization of MFCs.

Various electrode materials have been used to enhance the performance of MFCs including single metal electrodes to composite nanomaterials. In this review, material and architecture aspect of anode and cathode are discussed.

\section{Introduction to microbial fuel cells}

A fuel cell converts the chemical energy of a fuel into electrical energy without the need for combustion. MFCs are a type of electrochemical fuel cell in which the organic matter found in wastewater is oxidized by microorganisms. Conventionally, MFCs consist of an anode and a cathode separated by proton exchange membrane (PEM) such as Nafion and poly(tetrafluoroethylene) (PTFE). The schematic diagram of a typical MFC is shown in Fig. 1.

The bacterial biofilm produced at anode acts as catalyst to convert the chemical energy of the organic molecule into electrons while the oxygen gets reduced to form water at cathode $[10,11]$.

\section{Electron transfer mechanism}

The output power of a MFC depends on various factors including the type of organic matter present in the wastewater, electron transfer rate from bacteria to the anode and the efficiency of the membrane to transfer hydrogen ions [12]. Some microorganisms are known to deliver electrons from their oxidative metabolic pathways to their external environment, such microorganisms are called exoelectrogens [13]. Two major genera of bacteria are known for this ability; Geobacter and Shewanella. The extracellular transport of electrons to electrodes takes place in three different ways:

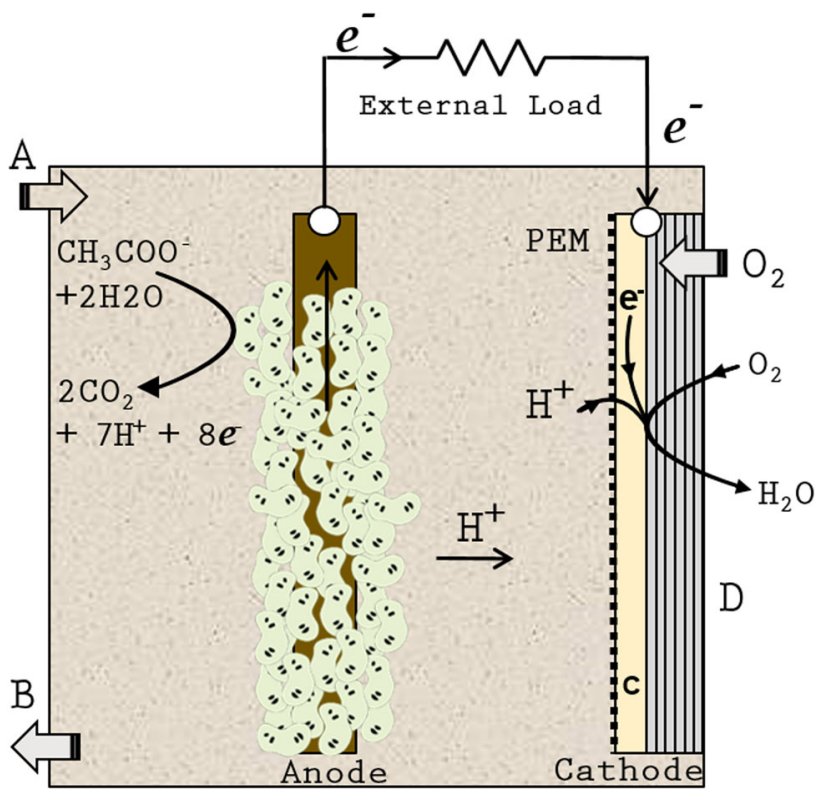

Fig. 1 A schematic of typical single chamber microbial fuel cell showing bacterial biofilm at anode, air cathode with diffusion layers. $A$ Effluent inlet, $B$ effluent outlet, $C$ catalyst layer, $D$ diffusion layers

1. Direct electron transfer

2. Electron transfer through mediators and

3. Electron transfer through nanowires.

Direct electron transfer: This type of mechanism is found in the Shewanella, Geobacter species in which electrons are directly transferred to the electrode surface. The outer membrane cytochrome (C-type) is involved in the direct transfer of electrons produced from NADH [14]. Electron transfer through mediators: Few genera of bacteria such as Shewanella and Pseudomonas secrete some chemical species such as flavins called shuttle molecules to transfer electrons from the outer membrane of bacteria to electrodes $[15,16]$.

Electron transfer through nanowires: Geobacter genera and very recently Shewanella are reported to use conductive appendages for electron transfer outside the cell [17, 18]. These conductive networks are cellular outgrowth, as long as $20 \mu \mathrm{m}$, termed as nanowires. It is reported that the electronic conductivity of these nanowires is much higher than synthetic metallic nanostructure [19]. Schaetzle et al. suggested fourth mechanism of electron transport by oxidizing the excreted catabolites by the bacteria [20]

\section{Biochemical cell reactions}

In MFCs, organic molecules such as acetate and glucose are oxidized to produce electrons, which travel down to an external circuit, producing power. The emf produced by an MFC can be calculated as: 
$E_{\text {emf }}=E_{\text {cathode }}-E_{\text {anode }}-\eta$

where $E_{\text {cathode }}, E_{\text {anode }}$ and $\eta$ are the half cell potential at the cathode, the half cell potential at the anode and a loss term, respectively [21]. The loss term includes ohmic losses, which are more dominant, activation losses and mass transfer losses. The oxidation reaction (sodium acetate) at anode and oxygen reduction reaction at cathode can be written as:

$$
\begin{aligned}
& \mathrm{CH}_{3} \mathrm{COO}^{-}+2 \mathrm{H}_{2} \mathrm{O} \longrightarrow 2 \mathrm{CO}_{2}+7 \mathrm{H}^{+}+8 \mathrm{e}^{-} \\
& \mathrm{O}_{2}+4 \mathrm{H}^{+}+4 \mathrm{e}^{-} \longrightarrow 2 \mathrm{H}_{2} \mathrm{O}
\end{aligned}
$$

According to the Nernst equation, the half cell potential can be calculated as:

$$
E_{\text {halfcell }}=E_{0}-\frac{R T}{n F} \ln Q
$$

where $E_{0}, R, T, Q$ are the standard half cell potential, the gas constant, the temperature in Kelvin and the activity constant, respectively.

The feasible energy produced by the electrochemical system can be calculated using the Gibbs free energy equation as:

$$
\Delta G=-n F E_{\mathrm{emf}}
$$

where $n$ is number of electrons, $F$ is Faraday constant and $E_{\text {cell }}$ is cell voltage [22]. If the overall reaction is thermodynamically favored, the electricity is generated in the MFC following the Gibb's free energy equation.

\section{Electrode material}

The selection of the proper electrode material is crucial for the performance of MFCs in terms of bacterial adhesion, electron transfer and electrochemical efficiency. There are many studies to scale up the power production using different carbon-based materials such as carbon paper, carbon felt, carbon fiber as well as carbon nanotube-based composites. To implement the MFC technology in practice, the cost of materials must be reduced and power densities must be maximized. In addition, the cathode materials should have catalytic properties for oxygen reduction [23].

Although the criteria to select materials for the anode and cathode are different, in general both should possess the following properties:

Surface area and porosity: The output power of MFCs is greatly constrained by the surface area of electrodes. The ohmic losses are directly proportional to the resistance of the electrode. The easiest way to decrease the resistance is to increase the effective surface area while keeping the volume the same, hence enhancing the efficiency of the
MFC. Furthermore, a high surface area provides more sites for reactions, enhancing electrode kinetics [24] [25]. However, porosity will decrease the electrical conductivity of the material.

Electrical conductivity: Electrons released from microbes have to travel along an external circuit after passing through the anode. The high electrical conductivity of the electrode material makes the electron flow with less resistance. At the same time, the interfacial impedance should be low to facilitate the electron transfer. At the cathode, the ionic conductivity is also required to facilitate triple phase boundary reaction [26].

Stability and durability: The reducing and oxidizing environment in an MFC may lead to the swelling and decomposition of the materials. The high surface roughness increases the durability of the material while it might increase the chances of fouling, thus may decrease the long-term performance of the MFC. Therefore, the material for electrodes should be durable as well as stable in an acidic and a basic environment. Cost and accessibility: The cost of the electrode material influences the capital cost of the MFC to a large extent. To commercialize the MFC, the material should be low cost, sustainable and easily available. Some metals like platinum are highly expensive, non-durable and nonsustainable as well. Non-precious metal materials such as composites might be an alternative to substitute precious metals in electrodes in the future.

In addition, materials used for the anode must have biocompatible properties. A superior biocompatible material will increase the bacterial adhesion and hence the life of the MFC.

\section{Anode material}

The anode material significantly impacts the biofilm formation and the electron transfer between the microorganism and the electron acceptor. Various materials used in an MFC including carbon rods, carbon cloth, carbon fiber, stainless steel mesh are summarized in the following sections.

\section{Conventional carbon-based materials}

Carbonaceous materials such as graphite rods and graphite brushes, carbon cloth, carbon paper, carbon felt and reticulated vitreous carbon are widely used as anodes in MFCs because of their high electrical conductivity, specific surface area, biocompatibility, chemical stability and low cost $[27,28]$. Different electrode materials used as anodes are shown in Fig. 2. 
Fig. 2 a Typical graphite rod electrode, $\mathbf{b}$ carbon fiber brush electrode [29], c carbon cloth electrode, $\mathbf{d}$ carbon felt electrode [27]
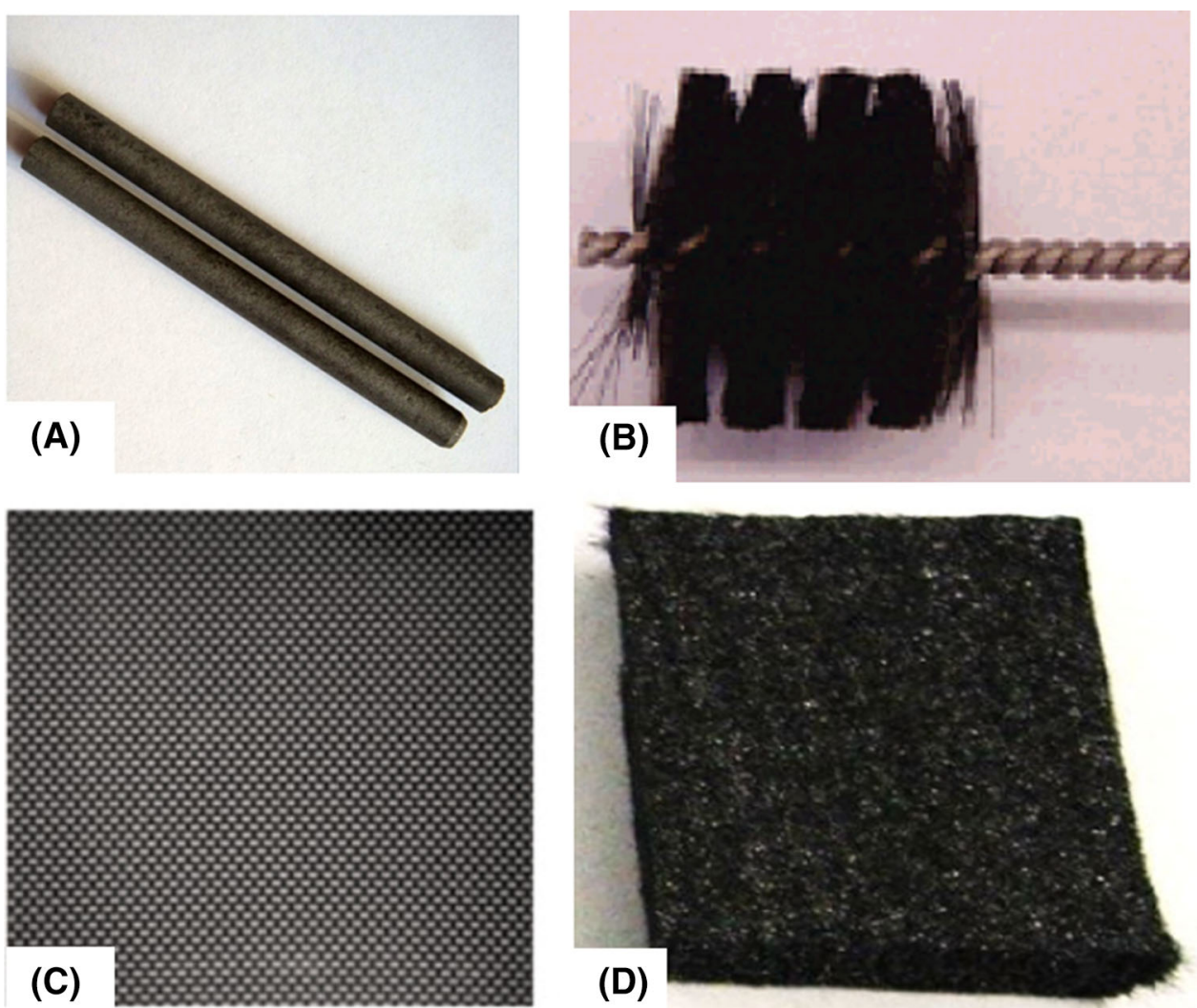

Liu et al. used eight graphite anodes with a single cathode in a single-chambered MFC and observed a decrease of chemical oxygen demand by $80 \%$ from the initial value. Although, the maximum power obtained was less ca. $26 \mathrm{~mW} / \mathrm{m}^{2}$. The low porosity of carbon rods limits its wide application in MFCs [12]. Lovley and coworkers solved this problem using similar materials with higher surface areas such as graphite felt electrodes and showed that the maximum current produced was increased by three times because of an increase in electrode surface area [30]. One other approach adopted by Logan et al. involved using a graphite fiber brush electrode wound around a titanium wire to increase the surface area and microbial inoculation. The maximum power density was measured to be up to $2400 \mathrm{~mW} / \mathrm{m}^{2}$, which was around four times higher than that of carbon paper [29, 31]. Carbon cloth, another similar material, showed a maximum power density of up to 483 $\mathrm{mW} / \mathrm{m}^{2}$ [32].

A three-dimensional, ultra-met, chemically and thermally resistant material called reticulated vitreous carbon (RVC) was used by $\mathrm{He}$ et al. This material was proven to be biocompatible as demonstrated by Pec et al. using cell viability studies [33]. Carbon mesh electrodes were used by Wang and co-workers because of their low cost [34]. The power density was increased to $1015 \mathrm{~mW} / \mathrm{m}^{2}$, which was higher than that of carbon cloth. In Fig. 3, the performance

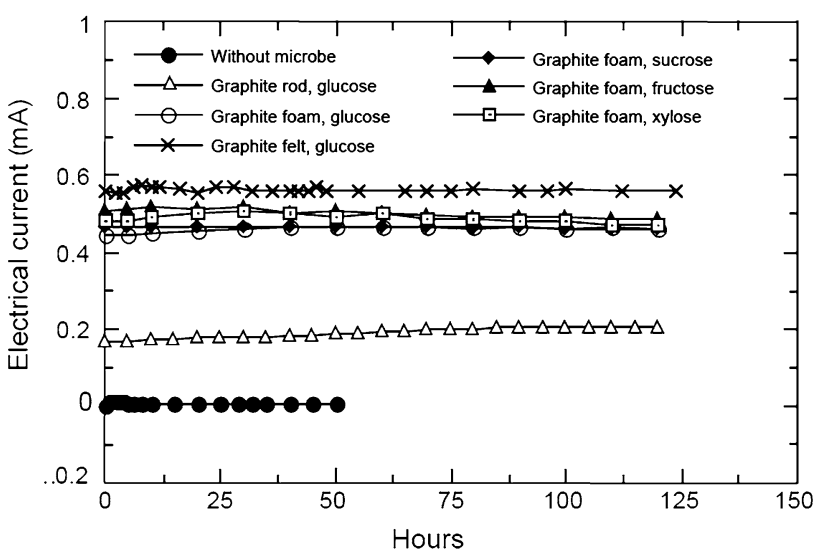

Fig. 3 Current output of different carbon-based anodes-graphite rod, graphite felt, graphite foam at anode voltage $0.445 \mathrm{~V}\left(25^{\circ} \mathrm{C}\right)$. The geometrical surface area of graphite rod, $6.5 \times 10^{-} 3 \mathrm{~m}^{2}$; graphite felt, $20 \times 10^{-} 3 \mathrm{~m}^{2}$; graphite foam, $6.1 \times 10^{-} 3 \mathrm{~m}^{2}$ [30]

of conventional carbon-based materials is shown. It is clear from the plot that graphite foam with same geometrical area as graphite rod showed 2.4 times more current (current density: $74 \mathrm{~mA} / \mathrm{m}^{2}$, voltage: $445 \mathrm{mV}$ ). A new type of filler anode was developed by Liang et al. through sintering of carbon felt and carbon paper, decreasing the resistance by decreasing the grain boundaries and hence enhancing the connection [35]. 


\section{CNT-based material}

Carbon nanotubes (CNTs), allotropes of carbon, have been shown to be promising alternative materials for MFC electrodes because of their unique electrical conductivity, chemical stability, biocompatibility, high specific area and also catalytic properties [36]. It is reported that CNTs have strong cell adhesion, cell attachment and growth properties $[37,38]$.

Very recently, Erbay et al. reported that microbes grown over CNTs result in excellent charge transfer characteristics due to $\pi-\pi$ stacking between the carbon atoms of graphite and the pili (a cellular outgrowth) of microorganisms [39]. CNTs can be grown directly over the stainless steel mesh to keep the ohmic resistance low. It was observed that the spaces between CNTs have the advantage of providing space for microbe inoculation. Furthermore, the minimum amount of amorphous carbon provides excellent charge interaction. Tsai et al. coated CNTs over the carbon cloth to form a highly conductive anode of MFC with a large surface area and found that the maximum power density was improved by 250 percent [40]. The properties of conventional anode materials used in MFCs are described in Table 1.

\section{Composite materials}

Recently, it was reported that CNTs incorporated with a conductive polymer can lead to a synergistic effect [46]. Qiao et al. showed that a CNT-polyaniline composite enhanced the electrocatalytic property and adhesion with the bacterial cell. They assumed that it was because of the protective effect of polyaniline and large increase in surface area. Other reports showed that CNTs deposition over carbon paper increases the power density by six times as compared to a graphite electrode [47]. Polypyrrole-coated CNTs were tested in a dual-chambered MFC and characterized by cyclic voltammetry. The result showed high peak current compared to the separation between the peak voltages, indicating that the polypyrrole-CNT composite increases the electrochemical active area [48]. In addition, polypyrrole-CNT showed a high electron transfer, which means that it is likely that PPy polymer might contain some molecular units similar to redox mediators [49].

When activated carbon is treated with concentrated nitric acid and ethylene diamine, the nitrogen to carbon ratio on the surface of the carbon fiber increases making bacterial adhesion more favorable [34, 50]. The glassy carbon electrode was coated with multiwall CNTs and used as an anode in an electrochemical setup, it was then reported that there was an increase in current density by a factor of 82 compared with a bare glassy carbon electrode using the same experimental conditions. Additionally, it was found that the multiwalled CNTs increase the outer membrane cytochrome electron kinetics [51]. Since anodes are employed directly with the bacterial inoculum, they are prone to swelling and degradation. In addition, their catalytic properties are limited. There is a need to modify such materials to obtain enhanced catalytic properties. Various treatments can be employed to improve the performance of carbon materials [52].

\section{Material treatments}

Surface treatment: Various surface treatments for anode materials in MFCs have been investigated to enhance the adhesion with microorganisms. The ammonia treatment is common among surface treatments. Ammonia treatment increases the adhesiveness between the bacteria and the electrode surface [50]. Cheng et al. showed that the ammonia-treated electrode greatly increased the power density by $48 \%$ and reduced the start-up time of the MFC from 150 to $60 \mathrm{~h} \mathrm{[50].} \mathrm{Zhang} \mathrm{et} \mathrm{al.} \mathrm{modified} \mathrm{the}$ stainless steel mesh anode with graphene and observed a power density of $2668 \mathrm{~mW} / \mathrm{m}^{2}$, which was 18 times higher than a plain stainless steel mesh electrode [53].

Acid treatment: When the electrode surface is treated with concentrated inorganic acids, it results in the

Table 1 Different materials used for MFC anode with their advantage and limitations

\begin{tabular}{|c|c|c|c|}
\hline Anode material & Advantage & Disadvantage & References \\
\hline Stainless steel & $\begin{array}{l}\text { High conductivity, relatively cheaper, } \\
\text { easy accessibility }\end{array}$ & $\begin{array}{l}\text { Low surface area, biocompatibility issues, } \\
\text { corrosion }\end{array}$ & {$[41]$} \\
\hline Graphite rod & $\begin{array}{l}\text { High conductivity and chemical stability, } \\
\text { relatively cheaper, easy accessibility }\end{array}$ & Difficult to increase surface area & [12] \\
\hline Graphite fiber brush & High specific area and easy construction & Clogging & {$[31]$} \\
\hline Carbon cloth & Large relative porosity & Relatively expensive & {$[42]$} \\
\hline Carbon paper & Easy wire connection & Fragile & {$[43]$} \\
\hline Carbon Felt & Large surface area & High resistance & [44] \\
\hline RVC & High electrical conductivity & Fragile, large resistance & [45] \\
\hline
\end{tabular}


protonation of functional groups over the electrode surface, as such increasing the number of positive charges over the surface of the electrode. Further, acid treatment leads to creation of cracks (roughness) in the material which also enhance the performance [54]. This treatment is very effective in combination with heat treatment. Feng et al. showed that by using a combination of heat and acid treatment, which result in an increase in power production by $25 \%$ [55].

Electrochemical oxidation treatment: Electrochemical oxidation treatment created new functional groups over the surface. The bacteria form peptide bonds with electrodes and therefore create a pathway for the effective transfer of electrons. It has been shown that the use of acid treatment can increase the power density by 57 percent [56].

\section{Cathode material}

In MFC, the oxygen is reduced at the three-phase interface of air (gas), electrolyte (liquid) and electrode (solid) to form water (four electron pathway) or hydrogen peroxide (two electron pathway). A typical MFC cathode has three layers, viz., diffusion layer (DL), conducting support material and catalyst. Figure 4 shows the three-phase interface of the cathode; the catalyst layer, electrode base material and oxygen diffusion layer. Most of the materials used as an anode can be used as a cathode however in addition a robust MFC cathode should have the following properties:

(a) High mechanical strength.

(b) Catalytic property.

(c) High electronic and ionic conductivity.

A low oxygen reduction rate at a neutral $\mathrm{pH}$ and low temperature results in a high over potential, which is a major limitation in MFC performance. Since carbon-based

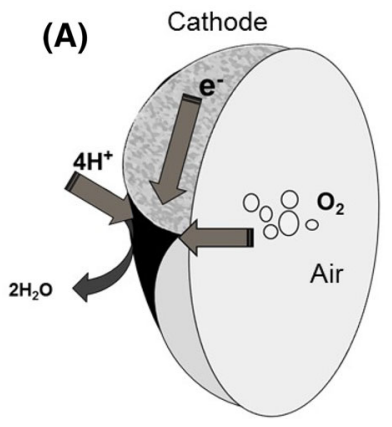

(B)

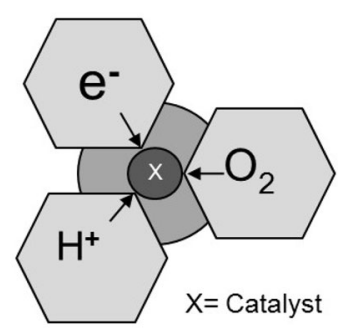

$4 \mathrm{H}^{+}+\mathrm{O}_{2}+4 \mathrm{e}^{-}->2 \mathrm{H}_{2} \mathrm{O}$

Fig. 4 The reaction at the cathode occurs at the triple phase interface of air, solution and catalyst. $a$ Oxygen reduction reaction at threephase interface producing water as product. $b$ ORR at three-phase interface of cathode materials have poor catalytic activity, an additional catalyst is required to boost the reduction process.

A catalyst increases the rate of reduction reaction by decreasing the activation energy barrier. Oxygen reduction reaction (ORR) follows two different pathways: one is the 4-electron pathway which is more favorable than the other 2-electron pathway [57]. The whole mechanism is described elsewhere in [58]. The ORR in two different electron pathways in acidic medium [59] can be expressed as:

$$
\begin{array}{r}
\mathrm{O}_{2}+4 \mathrm{H}^{+}+4 \mathrm{e}^{-} \longrightarrow 2 \mathrm{H}_{2} \mathrm{O} \\
\mathrm{O}_{2}+2 \mathrm{H}^{+}+2 \mathrm{e}^{-} \longrightarrow \mathrm{H}_{2} \mathrm{O}_{2} \\
\mathrm{H}_{2} \mathrm{O}_{2}+2 \mathrm{H}^{+}+2 \mathrm{e}^{-} \longrightarrow 2 \mathrm{H}_{2} \mathrm{O}
\end{array}
$$

Different materials used in an MFC cathode are summarized in the following sections.

\section{Cathode with Pt-based catalyst}

Oxygen reduction reaction is insufficient if plain carbon or graphite is used as the cathode. Therefore, it is necessary to coat it with a catalyst layer. In almost all cases, platinum is the most successful catalyst for oxygen reduction reaction because of its high surface area and low over potential for ORR [10]. Zhang et al. used a cathode made of a double layer of PDMS/carbon loaded with $\mathrm{Pt}$ and showed that a maximum power density of $1610 \mathrm{~mW} / \mathrm{m}^{2}$ can be achieved. Further, hydrophobic materials like PDMS decrease the water diffusion into a single-chambered MFC.

Ghasemi et al. reduced the Pt loading by depositing over CNTs, showing that the ORR catalytic activity was improved for CNT-Pt composite. Further, the ORR was not affected considerably by decreasing Pt loading by 20-fold [60, 61].

\section{Cathode with non-Pt-based catalyst}

Usually, Pt is the most used catalyst at the cathode but its high cost limits its use in commercial applications. Furthermore, some limitations with $\mathrm{Pt}$ include $\mathrm{pH}$ sensitivity, sulfide poisoning and non-sustainability challenged researchers to develop non-Pt-based catalysts as an alternative.

Another transition metal catalyst iron phthalocyanine can be used as a catalyst, taking the advantage of the $\pi-\pi$ interaction between the metal and carbon of the aromatic ring, leading to rapid electron transfer [62]. Yuan et al. reported the use of amino functionalized multiwalled CNTs supported with iron phthalocyanine for cathodes. The power density was considerably high with CNT cathodes. It was found that the power density achieved was even higher than platinum-carbon cathodes as shown in Fig. 5 [62]. Metal macrocyclic compounds such as cobalt 
tetramethoxyphenylporphyrin (CoTMPP), was used by Cheng et al. showed that CoTMPP can be used as an ORR catalyst with comparable coulombic efficiency to that of platinum [63]. Lead dioxide can also be used as an alternative to $\mathrm{Pt}$ as a catalyst, while having a lower cost, it also shows four times higher power densities as compared to conventional Pt electrodes [64].

Transition metal-based oxide catalysts have also emerged as an alternative to platinum in ORR [65]. Manganese dioxide $\mathrm{MnO}_{2}$ has been used as a shuttling mechanism for oxygen reduction. The cathode current of a $\mathrm{MnO}_{2}$ catalyzed cathode was found to be much larger than a graphite electrode [66]. The results were pursued by

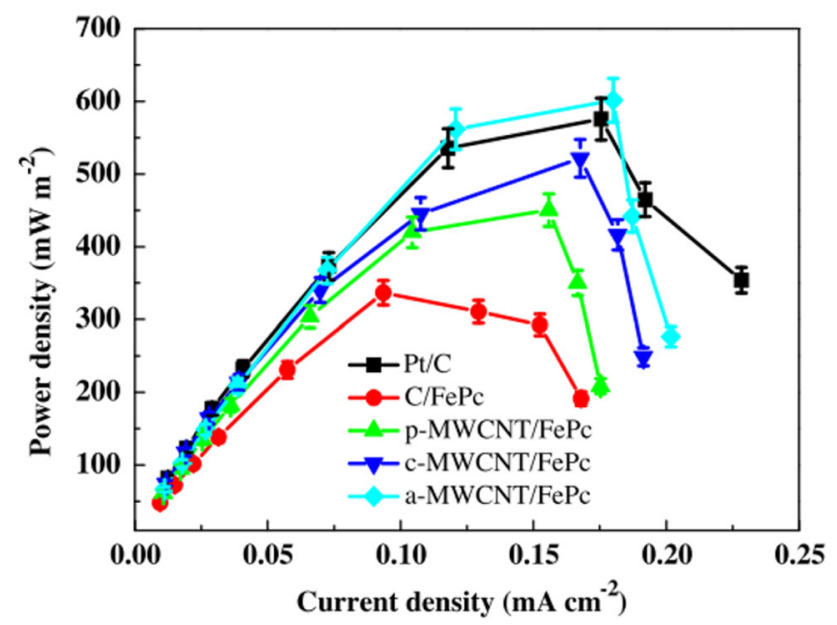

Fig. 5 Power density of MFC cathode using CNT composite material iron phthalocyanine (FePc), Pt and carbon electrode is compared. It is shown that amino functionalized CNT-FePc composite material has almost same power density as $\mathrm{Pt} / \mathrm{C}[62]$
Zhang et al. by comparing the three forms of manganese dioxide $\alpha, \beta$ and $\gamma \mathrm{MnO}_{2}$ deposited over glassy carbon using polyvinylidene fluorine (PVDF) as binder. Results showed that the catalytic properties of $\beta \mathrm{MnO}_{2}$ are quite close to platinum catalyst as shown in Fig. 6b [67]. Further, Fig. 6a also shows that power densities of $\mathrm{MnO}_{2}$ as catalyst are very close to standard $\mathrm{Pt}$ as catalyst. During ORR, the $\mathrm{MnO}_{2}$ is first reduced to $\mathrm{MnOOH}$ by accepting electrons, which is then followed by oxidation to $\mathrm{MnO}_{2}$. Furthermore, the current density of ORR from $\mathrm{MnO}_{2}$ deposited cathode was 10 times higher than that of glassy carbon, indicating the ORR catalytic property of $\mathrm{MnO}_{2}$. Similar results were also reported by Roche et al. with $\mathrm{MnO}_{2}$ cathode deposited over carbon black as shown in Fig. 6 [68]. Amade et al. used manganese dioxide deposited over CNTs as a cathode material showed that the output power density increased by two orders of magnitude as compared to plain stainless steel cathode [69].

Recently, palladium, a Pt-like transition metal, is being tested for use as a cathode due to its excellent catalytic properties and low cost. Huang et al. showed that Pd nanoparticle has a very low oxygen reduction reaction overpotential for catalytic hydrogen production. The linear sweep voltammetry results show higher stability than that of Pt [70].

Lead oxide is also used as an alternative catalyst for MFC cathodes. Some very interesting results obtained by Morris et al. show that power densities were increased to four times than that of commercial $\mathrm{Pt} / \mathrm{C}(10 \mathrm{wt} \%)$. Furthermore, the cost of $\mathrm{PbO}_{2}$ electrodes was 8 times less than Pt-carbon electrode [64]. Activated carbon with large surface areas can be synthesized by electrospinning and pyrolysis of polyacrylonitrile precursor. It is reported by Ghasemi et al. that the power density of activated carbon

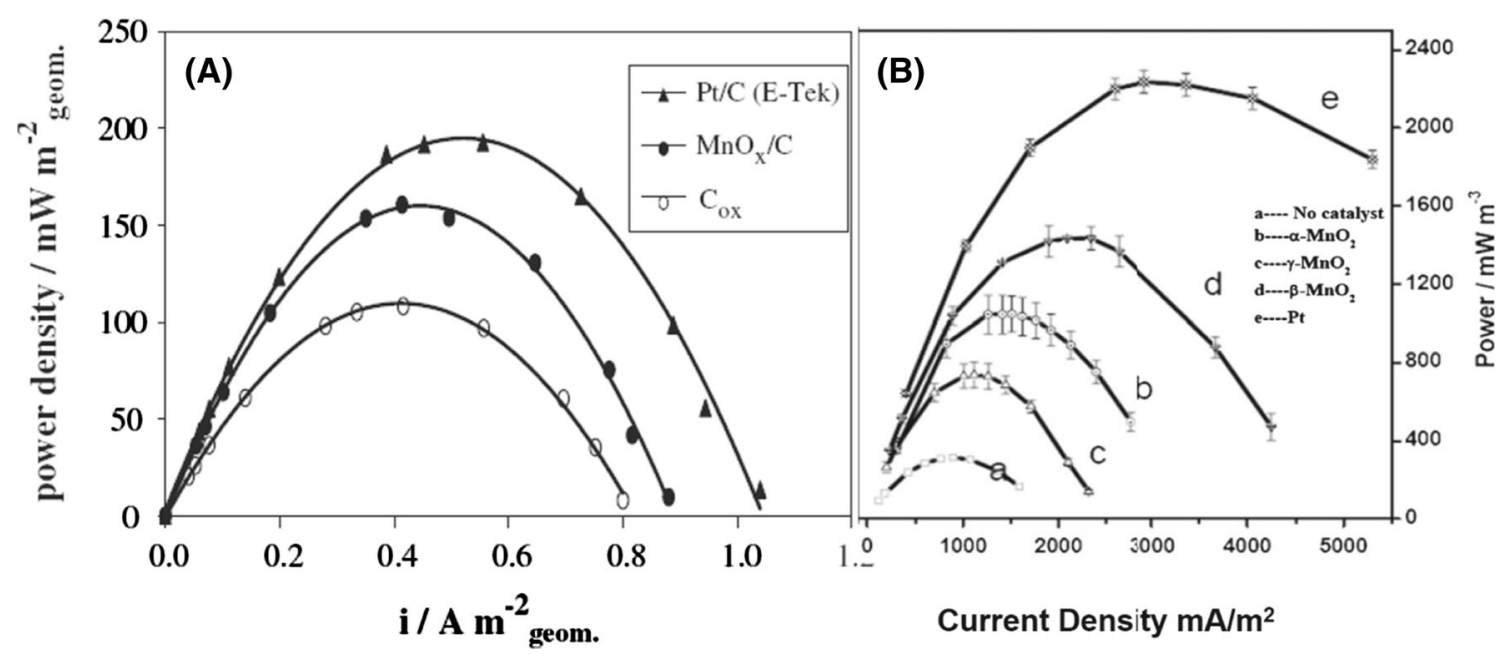

Fig. 6 Power density of cathode using $\mathrm{MnO}_{2}$ as catalyst is compared with standard $\mathrm{Pt} / \mathrm{C}(40 \mathrm{wt} \%)$ and without catalyst cathodes. a plot shows power density of $\mathrm{MnO}_{2}$ as cathode catalyst and $\mathbf{b}$ shows power density comparison of three forms of $\mathrm{MnO}_{2}$ with commercial $\mathrm{Pt} / \mathrm{C}$ material $[67,68]$ 


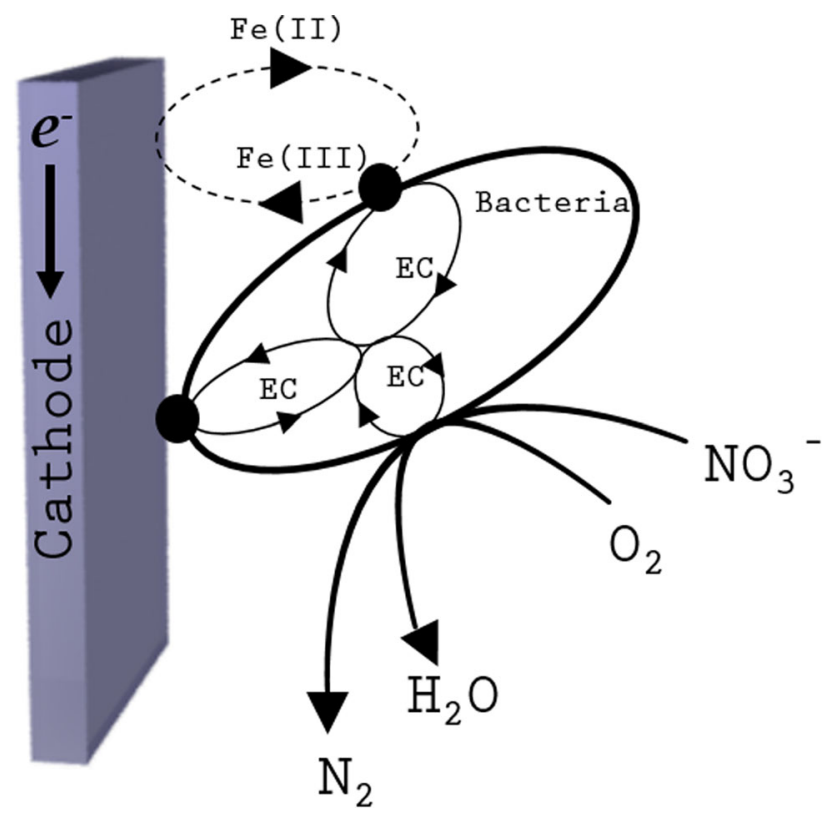

Fig. 7 MFC biocathode where oxygen and nitrate is reduced using direct electron transfer or using mediator. Manganese and iron act as mediators to transfer electrons to oxygen

fiber-treated electrodes was increased by more than 75 percent [60].

\section{Biocathode}

The higher cost, non-environmental friendly and complexity in fabrication of conventional catalysts lead to the development of biocathodes where microorganisms themselves act as the catalyst. The biofilm formed over the cathode catalyzes the reduction reaction [71].

Biocathodes can be categorized into two groups: aerobic and anaerobic biocathodes. In aerobic biocathodes, oxygen is a terminal electron acceptor and hydrogen peroxide is an intermediate. Transition metals such as iron and manganese act as electron mediators between the electrode and oxygen. Fe (III) is reduced to Fe (II) by electrons generated from the biofilm, which is subsequently oxidized by oxygen. In this way, electrons are transferred from the cathode to the terminal electron acceptor, oxygen in this case [72]. In anaerobic type conditions, where oxygen is not present, nitrates and sulfates can be terminal electron acceptors. Figure 7 shows a biocathode in which biofilm catalyze the reduction of chemical active species such as nitrate and oxygen. The cathodic potentials of nitrate, manganese and iron are comparable to oxygen. In addition, an anaerobic biocathode has the advantage by preventing the loss of electrons through oxygen, which may diffuse to the anode through PEM.

Furthermore, microorganisms at the cathode can be used to produce chemicals such as methane, ethanol and

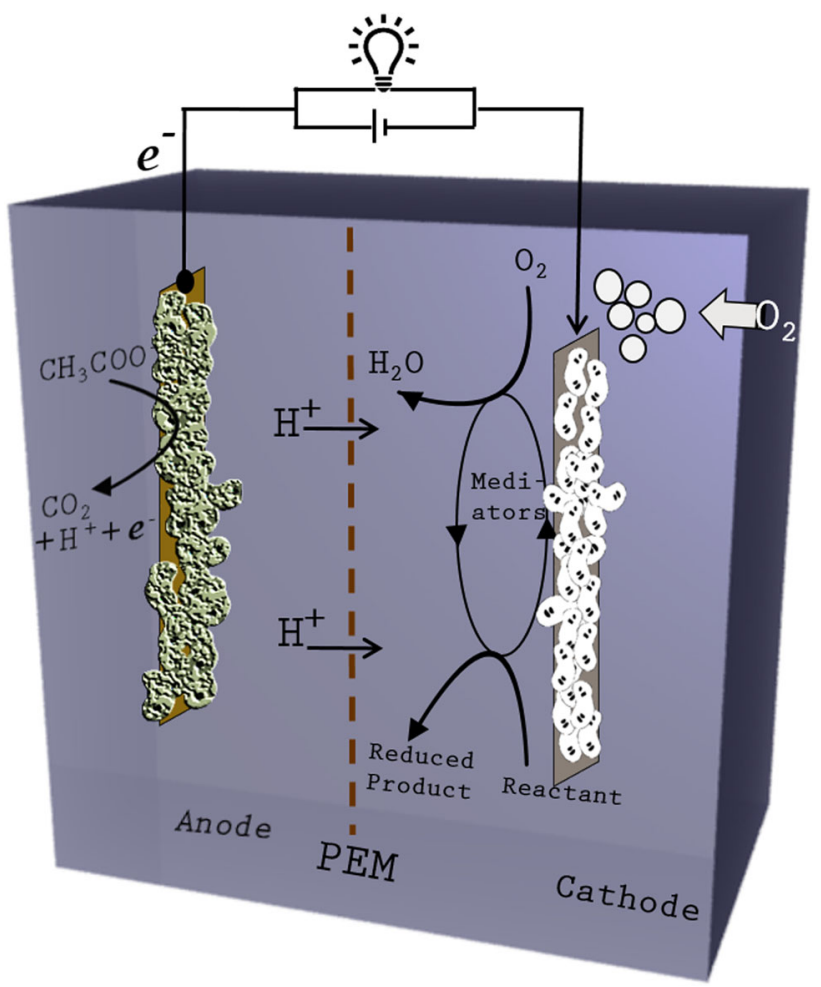

Fig. 8 A typical setup of MFC using a biocathode, where oxygen and chemical reactants are reduced. The system can be used to generate power or to drive biochemical synthesis reactions to synthesis valueadded chemicals

formic acid [73] and can also be used as a biosensor to detect biological oxygen demand (BOD) [74] in water. It is observed that a small amount of non-exoelectrogens are advantageous to facilitate the ORR by exoelectrogens [75]. A typical setup of an MFC using microorganisms as catalysts at the cathode with or without the help of manganese and iron mediator is shown in Fig. 8

It is also proved from cyclic voltammetry that biofilm formation is most facilitated by graphite felt followed by carbon paper and stainless steel mesh [76].

\section{Cathode with metal-free catalyst}

The higher cost of metal catalyst along with limited global reserve appealed researchers to find an alternative with comparable catalytic activity, less expensive materials for ORR at cathode. Recently, it was reported that metals as catalyst in ORR only promote the formation of active sites and have no role in catalytic function [77]. Chemically modified carbon-based materials including carbon nanotubes, graphene, graphite foam can be used as catalyst for ORR $[78,79]$. ORR can proceed to four electron pathway using a nitrogen incorporated catalysts [80-82]. Nitrogendoped graphene nanosheets have shown high catalytic activity, stability and onset potential than commercially 


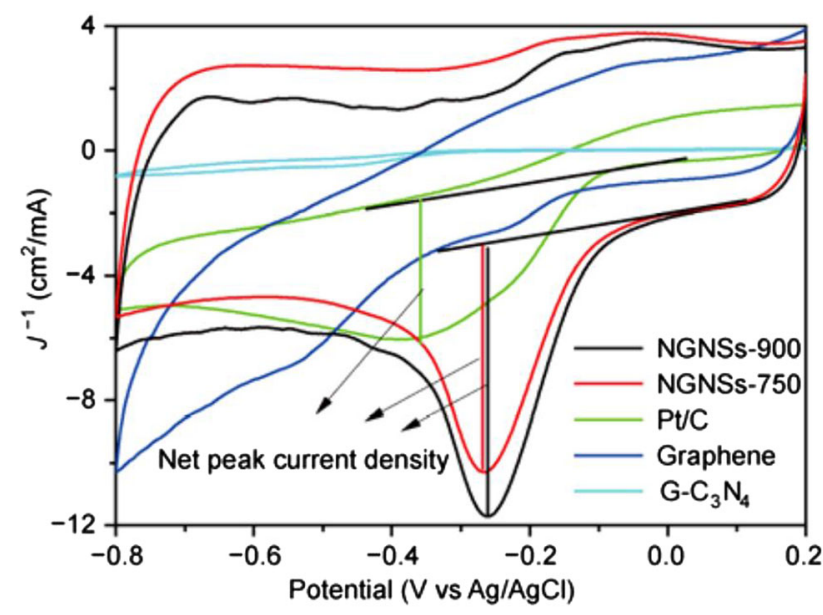

Fig. 9 Cyclic voltammograms of nitrogen-doped graphene nanosheets annealed at $900{ }^{\circ} \mathrm{C}$ (NGNSs-900), nitrogen-doped graphene nanosheets annealed at $750{ }^{\circ} \mathrm{C}$ (NGNSs-750), commercial $\mathrm{Pt} / \mathrm{C}(10 \mathrm{wt} \%)$, graphene and $\mathrm{C}_{3} \mathrm{~N}_{4}$ coated graphene performed in $0.1 \mathrm{M} \mathrm{KOH}$ solution with potential range -0.8 to +0.2 and scan rate $50 \mathrm{mV} / \mathrm{s}$ [83]

available Pt (10 wt\%) for ORR [81, 83]. In another study, nitrogen-doped CNTs were found to have higher electrocatalytic activity, lower overpotential and long-term stability for ORR than commercially available Pt $(20 \mathrm{wt} \%$, ETEK) [84]. In Fig. 9, the cyclic voltammogram of nitrogendoped graphene nanosheets is compared with other materials. It is clear from the figure that the nitrogen-doped graphene nanosheets show the best catalytic activity compared to other materials. The net peak current density approaches to $8.75 \mathrm{~mA} / \mathrm{cm}^{2}$ for NGNSs-900 which is higher than commercial $\mathrm{Pt} / \mathrm{C}\left(5.12 \mathrm{~mA} / \mathrm{cm}^{2}\right)$.

It is proposed in many studies that carbon atom around nitrogen acts as active site for ORR. The higher electronegativity of nitrogen atom withdraws electrons from adjacent carbon atom creating positive carbon atom which acts as active site for activation of $\mathrm{O}_{2}$ molecule in ORR [85].

\section{Conclusion}

Electrode materials have a great impact on the performance of MFCs. Since cathodes and anodes have different characteristics, the materials and design for them also differ. In general, electrode materials are considered in terms of surface area, electronic conductivity, chemical stability, cost and accessibility. In addition, an anode material should be biocompatible to allow microorganisms to grow. Materials with cell toxicity cannot be used regardless of their other properties. Carbon-based materials are widely used because of their high conductivity, biocompatibility, chemical stability as well as low cost. Furthermore, the surface treatment of the anode leads to a better performance of the MFC. On the other hand, the cathode materials require enhanced catalytic properties due to the poor kinetics of oxygen reduction reaction. Even though platinum is the best catalyst, research is ongoing to find alternative materials due to its high cost, making it unfeasible to implement in commercial applications. Transition metal oxides such as manganese oxide, nitrogen-doped carbon-based materials have emerged as promising materials for ORR with low cost. Due to a lack of sustainable catalytic materials, microorganisms can also be used as catalysts, which is termed as a biocathode. In the future, microorganisms can be manipulated to increase their endogenous mediators for improved electron transfer. Lastly, a better understanding of microorganism interactions with electrode surfaces will be helpful to optimize the performance of the MFCs.

Acknowledgments The Author is grateful to Professor Enrico Traversa and Professor Peng Wang for their guidance throughout this work.

Open Access This article is distributed under the terms of the Creative Commons Attribution 4.0 International License (http:// creativecommons.org/licenses/by/4.0/), which permits unrestricted use, distribution, and reproduction in any medium, provided you give appropriate credit to the original author(s) and the source, provide a link to the Creative Commons license, and indicate if changes were made.

\section{References}

1. Chu, S., Majumdar, A.: Opportunities and challenges for a sustainable energy future. Nature 488(7411), 294 (2012). http:// www.nature.com/nature/journal/v488/n7411/pdf/nature11475.pdf

2. Funabashi, Y., Kitazawa, K.: Fukushima in review: a complex disaster, a disastrous response. Bull. At. Sci. 68(2), 9 (2012)

3. Williams, S.E., et al.: Energy usage comparison between activated sludge treatment and rotating biological contactor treatment of municipal wastewater. www.williams-works.com (2012)

4. Potter, M.C.: Electrical effects accompanying the decomposition of organic compounds. Proc. R. Soc. Lond. Ser. B Contain. Pap. Biol. Character, pp. 260-276 (1911)

5. Shukla, A., Suresh, P., Berchmans, S., Rajendran, A.: Biological fuel cells and their applications. Curr. Sci. 87(4), 455 (2004)

6. Lovley, D.R.: Bug juice: harvesting electricity with microorganisms. Nat. Rev. Microbiol. 4(7), 497 (2006)

7. Kim, B.H., Kim, H.J., Hyun, M.S., Park, D.H.: Direct electrode reaction of $\mathrm{Fe}$ (III)-reducing bacterium, Shewanella putrefaciens. J. Microbiol. Biotechnol. 9(2), 127 (1999)

8. Rabaey, K., Verstraete, W.: Microbial fuel cells novel biotechnology for energy generation. Trends Biotechnol. 23(6), 291 (2005)

9. Min, B., Logan, B.E.: Continuous electricity generation from domestic wastewater and organic substrates in a flat plate microbial fuel cell. Environ. Sci. Technol. 38(21), 5809 (2004)

10. Watanabe, K.: Recent developments in microbial fuel cell technologies for sustainable bioenergy. J. Biosci. Bioeng. 106(6), 528 (2008) 
11. Zhou, M., Wang, H., Hassett, D.J., Gu, T.: ecent advances in microbial fuel cells (MFCs) and microbial electrolysis cells (MECs) for wastewater treatment, bioenergy and bioproducts. J. Chem. Technol. Biotechnol. 88(4), 508 (2013)

12. Liu, H., Cheng, S., Logan, B.E.: Power generation in fed-batch microbial fuel cells as a function of ionic strength, temperature, and reactor configuration. Environ. Sci. Technol. 39(14), 5488 (2005)

13. Reguera, G., McCarthy, K.D., Mehta, T., Nicoll, J.S., Tuominen, M.T., Lovley, D.R.: Extracellular electron transfer via microbial nanowires. Nature 435(7045), 1098 (2005)

14. Lies, D.P., Hernandez, M.E., Kappler, A., Mielke, R.E., Gralnick, J.A., Newman, D.K.: Shewanella oneidensis MR-1 uses overlapping pathways for iron reduction at a distance and by direct contact under conditions relevant for biofilms. Appl. Environ. Microbiol. 71(8), 4414 (2005)

15. Yang, Y., Xu, M., Guo, J., Sun, G.: Bacterial extracellular electron transfer in bioelectrochemical systems. Process Biochem. 47(12), 1707 (2012)

16. Schröder, U.: Anodic electron transfer mechanisms in microbial fuel cells and their energy efficiency. Phys. Chem. Chem. Phys. 9(21), 2619 (2007)

17. El-Naggar, M.Y., Wanger, G., Leung, K.M., Yuzvinsky, T.D., Southam, G., Yang, J., Lau, W.M., Nealson, K.H., Gorby, Y.A.: Electrical transport along bacterial nanowires from Shewanella oneidensis MR-1. Proc. Natl. Acad. Sci. 107(42), 18127 (2010)

18. Gorby, Y.A., Yanina, S., McLean, J.S., Rosso, K.M., Moyles, D., Dohnalkova, A., Beveridge, T.J., Chang, I.S., Kim, B.H., Kim, K.S., et al.: Electrically conductive bacterial nanowires produced by Shewanella oneidensis strain MR-1 and other microorganisms. Proc. Natl. Acad. Sci. 103(30), 11358 (2006)

19. Malvankar, N.S., Vargas, M., Nevin, K.P., Franks, A.E., Leang, C., Kim, B.C., Inoue, K., Mester, T., Covalla, S.F., Johnson, J.P., et al.: Tunable metallic-like conductivity in microbial nanowire networks. Nat. Nanotechnol. 6(9), 573 (2011)

20. Schaetzle, O., Barrière, F., Schröder, U.: An improved microbial fuel cell with laccase as the oxygen reduction catalyst. Energy Environ. Sci. 2(1), 96 (2009)

21. Hoogers, G.: Fuel cell technology handbook, CRC Press (2014)

22. Worrell, J.H.: Inorganic chemistry an industrial and environmental perspective. J. Chem. Educ. 74(12), 1399 (1997)

23. Logan, B.E.: Scaling up microbial fuel cells and other bioelectrochemical systems. Appl. Microbiol. Biotechnol. 85(6), 1665 (2010)

24. Wang, H.Y., Bernarda, A., Huang, C.Y., Lee, D.J., Chang, J.S.: Micro-sized microbial fuel cell: a mini-review. Bioresour. Technol. 102(1), 235 (2011)

25. Rismani-Yazdi, H., Carver, S.M., Christy, A.D., Tuovinen, O.H.: Cathodic limitations in microbial fuel cells: an overview. J. Power Sources 180(2), 683 (2008)

26. Natarajan, D., Van Nguyen, T.: Effect of electrode configuration and electronic conductivity on current density distribution measurements in PEM fuel cells. J. Power Sources 135(1), 95 (2004)

27. Wei, J., Liang, P., Huang, X.: Recent progress in electrodes for microbial fuel cells. Bioresour. Technol. 102(20), 9335 (2011)

28. Zhou, M., Chi, M., Luo, J., He, H., Jin, T.: An overview of electrode materials in microbial fuel cells. J. Power Sources 196(10), 4427 (2011)

29. Logan, B., Cheng, S., Watson, V., Estadt, G.: Graphite fiber brush anodes for increased power production in air-cathode microbial fuel cells. Environ. Sci. Technol. 41(9), 3341 (2007)

30. Chaudhuri, S.K., Lovley, D.R.: Electricity generation by direct oxidation of glucose in mediatorless microbial fuel cells. Nat. Biotechnol. 21(10), 1229 (2003)

31. Ahn, Y., Logan, B.E.: Effectiveness of domestic wastewater treatment using microbial fuel cells at ambient and mesophilic temperatures. Bioresour. Technol. 101(2), 469 (2010)
32. Wang, X., Feng, Y., Lee, H.: Electricity production from beer brewery wastewater using single chamber microbial fuel cell. Water Sci. Technol. 57(7), 1117 (2008)

33. Pec, M.K., Reyes, R., Snchez, E., Carballar, D., Delgado, A., Santamara, J., Arruebo, M., Evora, C.: Reticulated vitreous carbon a useful material for cell adhesion and tissue invasion. Eur. Cells Mater. 20, 282 (2010)

34. Wang, X., Cheng, S., Feng, Y., Merrill, M.D., Saito, T., Logan, B.E.: Use of carbon mesh anodes and the effect of different pretreatment methods on power production in microbial fuel cells. Environ. Sci. Technol. 43(17), 6870 (2009)

35. Liang, P., Fan, M.-Z., Cao, X.-X., Huang, X., Huang, Z.-H., Wang, C.: Electricity generation using the packing-type microbial fuel cells. Huan. Jing. Ke. Xue. 29, 512-517 (2008)

36. Iijima, S.: Helical microtubules of graphitic carbon. Nature 354(6348), 56 (1991). doi:10.1038/354056a0

37. Correa-Duarte, M.A., Wagner, N., Rojas-Chapana, J., Morsczeck, C., Thie, M., Giersig, M.: Fabrication and biocompatibility of carbon nanotube-based 3D networks as scaffolds for cell seeding and growth. Nano Lett. 4(11), 2233 (2004). doi:10.1021/ n1048574f

38. Heister, E., Brunner, E.W., Dieckmann, G.R., Jurewicz, I., Dalton, A.B.: Are carbon nanotubes a natural solution? Applications in biology and medicine. ACS Appl. Mater. Interfaces 5(6), 1870 (2013)

39. Erbay, C., Pu, X., Choi, W., Choi, M.J., Ryu, Y., Hou, H., Lin, F., de Figueiredo, P., Yu, C., Han, A.: Control of geometrical properties of carbon nanotube electrodes towards high-performance microbial fuel cells. J. Power Sources 280, 347 (2015)

40. Tsai, H.Y., Wu, C.C., Lee, C.Y., Shih, E.P.: Microbial fuel cell performance of multiwall carbon nanotubes on carbon cloth as electrodes. J. Power Sources 194(1), 199 (2009)

41. Dumas, C., Mollica, A., Fron, D., Bassguy, R., Etcheverry, L., Bergel, A.: Marine microbial fuel cell: use of stainless steel electrodes as anode and cathode materials. Electrochim. Acta 53(2), 468 (2007)

42. Ishii, S., Watanabe, K., Yabuki, S., Logan, B.E., Sekiguchi, Y.: Comparison of electrode reduction activities of Geobacter sulfurreducens and an enriched consortium in an air-cathode microbial fuel cell. Appl. Environ. Microbiol. 74(23), 7348 (2008)

43. Kim, J.R., Jung, S.H., Regan, J.M., Logan, B.E.: Electricity generation and microbial community analysis of alcohol powered microbial fuel cells. Bioresour. Technol. 98(13), 2568 (2007)

44. Kim, H.J., Park, H.S., Hyun, M.S., Chang, I.S., Kim, M., Kim, B.H.: A mediator-less microbial fuel cell using a metal reducing bacterium, Shewanella putrefaciens. Enzyme Microb. Technol. 30(2), 145 (2002)

45. He, Z., Minteer, S.D., Angenent, L.T.: Electricity generation from artificial wastewater using an upflow microbial fuel cell. Environ. Sci. Technol. 39(14), 5262 (2005)

46. Kymakis, E., Amaratunga, G.A.J.: Single wall carbon nanotube conjugated polymer photovoltaic devices. Appl. Phys. Lett. 80(1), 112 (2002)

47. Sharma, T., Mohana Reddy, A.L., Chandra, T.S., Ramaprabhu, S.: Development of carbon nanotubes and nanofluids based microbial fuel cell. Int. J. Hydrog. Energy 33(22), 6749 (2008)

48. Zou, Y., Xiang, C., Yang, L., Sun, L.X., Xu, F., Cao, Z.: A mediatorless microbial fuel cell using polypyrrole coated carbon nanotubes composite as anode material. Int. J. Hydrog. Energy 33(18), 4856 (2008)

49. Bai, F.W., Liu, C.G., Huang, H., Tsao, G.T.: Biotechnology in China III: biofuels and bioenergy, Springer (2012)

50. Cheng, S., Logan, B.E.:. Ammonia treatment of carbon cloth anodes to enhance power generation of microbial fuel cells. Electrochem. Commun. 9(3), 492 (2007) 
51. Peng, L., You, S.J., Wang, J.Y.: Carbon nanotubes as electrode modifier promoting direct electron transfer from Shewanella oneidensis. Biosens. Bioelectron. 25(5), 1248 (2010)

52. Kumar, G.G., Sarathi, V.G.S., Nahm, K.S.: Recent advances and challenges in the anode architecture and their modifications for the applications of microbial fuel cells. Biosens. Bioelectron. 43, 461 (2013). doi:10.1016/j.bios.2012.12.048

53. Zhang, Y., Mo, G., Li, X., Zhang, W., Zhang, J., Ye, J., Huang, X., Yu, C.: A graphene modified anode to improve the performance of microbial fuel cells. J. Power Sources 196(13), 5402 (2011)

54. Li, B., Zhou, J., Zhou, X., Wang, X., Li, B., Santoro, C., Grattieri, M., Babanova, S., Artyushkova, K., Atanassov, P., et al.: Mechanisms of the oxygen reduction reaction on defective graphene-supported Pt nanoparticles from first-principles. Electrochim. Acta 134, 116 (2014)

55. Feng, Y., Yang, Q., Wang, X., Logan, B.E.: Treatment of carbon fiber brush anodes for improving power generation in air-cathode microbial fuel cells. J. Power Sources 195(7), 1841 (2010)

56. Lowy, D.A., Tender, L.M., Zeikus, J.G., Park, D.H., Lovley, D.R.: Harvesting energy from the marine sediment-water interface II. Kinetic activity of anode materials. Biosens. Bioelectron. 21(11), 2058-2063 (2006). http://www.sciencedirect.com/science/ article/pii/S0956566306000431

57. Lim, D.H., Wilcox, J.: Mechanisms of the oxygen reduction reaction on defective graphene-supported Pt nanoparticles from first-principles. J. Phys. Chem. C 116(5), 3653 (2012)

58. Wang, Z., Cao, C., Zheng, Y., Chen, S., Zhao, F.: Abiotic oxygen reduction reaction catalysts used in microbial fuel cells. ChemElectroChem 1(11), 1813 (2014)

59. Erable, B., Féron, D., Bergel, A.: Microbial catalysis of the oxygen reduction reaction for microbial fuel cells: a review. ChemSusChem 5(6), 975 (2012)

60. Ghasemi, M., Shahgaldi, S., Ismail, M., Kim, B.H., Yaakob, Z., Wan Daud, W.R.: Activated carbon nanofibers as an alternative cathode catalyst to platinum in a two-chamber microbial fuel cell. Int. J. Hydrog. Energy 36(21), 13746 (2011). doi:10.1016/j. ijhydene.2011.07.118

61. Cheng, S., Liu, H., Logan, B.E.: Increased power generation in a continuous flow MFC with advective flow through the porous anode and reduced electrode spacing. Environ. Sci. Technol. 40(7), 2426 (2006)

62. Yuan, Y., Zhao, B., Jeon, Y., Zhong, S., Zhou, S., Kim, S.: Iron phthalocyanine supported on amino-functionalized multi-walled carbon nanotube as an alternative cathodic oxygen catalyst in microbial fuel cells. Bioresour. Technol. 102(10), 5849 (2011)

63. Cheng, S., Liu, H., Logan, B.E.: Power densities using different cathode catalysts (Pt and CoTMPP) and polymer binders (Nafion and PTFE) in single chamber microbial fuel cells. Environ. Sci. Technol. 40(1), 364 (2006)

64. Morris, J.M., Jin, S., Wang, J., Zhu, C., Urynowicz, M.A.: Lead dioxide as an alternative catalyst to platinum in microbial fuel cells. Electrochem. Commun. 9(7), 1730 (2007)

65. Antolini, E.: Composite materials for polymer electrolyte membrane microbial fuel cells. Biosens. Bioelectron. 69, 54 (2015)

66. Cao, Y.L., Yang, H.X., Ai, X.P., Xiao, L.F.: The mechanism of oxygen reduction on $\mathrm{MnO} 2$-catalyzed air cathode in alkaline solution. J. Electroanal. Chem. 557, 127 (2003). doi:10.1016/ S0022-0728(03)00355-3

67. Zhang, L., Liu, C., Zhuang, L., Li, W., Zhou, S., Zhang, J.: Manganese dioxide as an alternative cathodic catalyst to platinum in microbial fuel cells. Biosens. Bioelectron. 24(9), 2825 (2009)
68. Roche, I., Katuri, K., Scott, K.: A microbial fuel cell using manganese oxide oxygen reduction catalysts. J. Appl. Electrochem. 40(1), 13 (2010)

69. Amade, R., Vila-Costa, M., Hussain, S., Casamayor, E.O., Bertran, E.: Vertically aligned carbon nanotubes coated with manganese dioxide as cathode material for microbial fuel cells. J. Mater. Sci. 50(3), 1214 (2015)

70. Huang, Y.X., Liu, X.W., Sun, X.F., Sheng, G.P., Zhang, Y.Y., Yan, G.M., Wang, S.G., Xu, A.W., Yu, H.Q.: A new cathodic electrode deposit with palladium nanoparticles for cost-effective hydrogen production in a microbial electrolysis cell. Int. J. Hydrog. Energy 36(4), 2773 (2011)

71. Harnisch, F., Schröder, U.: From MFC to MXC: chemical and biological cathodes and their potential for microbial bioelectrochemical systems. Chem. Soc. Rev. 39(11), 4433 (2010)

72. Park, D.H., Zeikus, J.G.: Improved fuel cell and electrode designs for producing electricity from microbial degradation. Biotechnol. Bioeng. 81(3), 348 (2003)

73. Rabaey, K., Rozendal, R.A.: Microbial electrosynthesis-revisiting the electrical route for microbial production. Nat. Rev. Microbiol. 8(10), 706 (2010)

74. Kim, B.H., Chang, I.S., Gil, G.C., Park, H.S., Kim, H.J.: Novel BOD (biological oxygen demand) sensor using mediator-less microbial fuel cell. Biotechnol. Lett. 25(7), 541 (2003)

75. He, Z., Angenent, L.T.: Application of bacterial biocathodes in microbial fuel cells. Electroanalysis 18(19-20), 2009 (2006)

76. Zhang, Y., Sun, J., Hu, Y., Li, S., Xu, Q.: Bio-cathode materials evaluation in microbial fuel cells: a comparison of graphite felt, carbon paper and stainless steel mesh materials. Int. J. Hydrog. Energy 37(22), 16935 (2012)

77. Nallathambi, V., Lee, J.W., Kumaraguru, S.P., Wu, G., Popov, B.N.: Development of high performance carbon composite catalyst for oxygen reduction reaction in PEM proton exchange membrane fuel cells. J. Power Sources 183(1), 34 (2008)

78. Su, D.S., Zhang, J., Frank, B., Thomas, A., Wang, X., Paraknowitsch, J., Schlögl, R.: Metal-free heterogeneous catalysis for sustainable chemistry. ChemSusChem 3(2), 169 (2010)

79. Matter, P.H., Zhang, L., Ozkan, U.S.: The role of nanostructure in nitrogen-containing carbon catalysts for the oxygen reduction reaction. J. Catal. 239(1), 83 (2006)

80. Liu, Y., Liu, H., Wang, C., Hou, S.X., Yang, N.: Sustainable energy recovery in wastewater treatment by microbial fuel cells: stable power generation with nitrogen-doped graphene cathode. Environ. Sci. Technol. 47(23), 13889 (2013)

81. Qu, L., Liu, Y., Baek, J.B., Dai, L.: Nitrogen-doped graphene as efficient metal-free electrocatalyst for oxygen reduction in fuel cells. ACS Nano 4(3), 1321 (2010)

82. Feng, L., Yan, Y., Chen, Y., Wang, L.: Nitrogen-doped carbon nanotubes as efficient and durable metal-free cathodic catalysts for oxygen reduction in microbial fuel cells. Energy Environ. Sci. 4(5), 1892 (2011)

83. Ci, S., Wu, Y., Zou, J., Tang, L., Luo, S., Li, J., Wen, Z. Nitrogen-doped graphene nanosheets as high efficient catalysts for oxygen reduction reaction. Chin. Sci. Bull. 57(23), 3065 (2012)

84. Gong, K., Du, F., Xia, Z., Durstock, M., Dai, L.: Nitrogen-doped carbon nanotube arrays with high electrocatalytic activity for oxygen reduction. Science 323(5915), 760 (2009)

85. Lee, K.R., Lee, K.U., Lee, J.W., Ahn, B.T., Woo, S.I.: Electrochemical oxygen reduction on nitrogen doped graphene sheets in acid media. Electrochem. Commun. 12(8), 1052 (2010) 